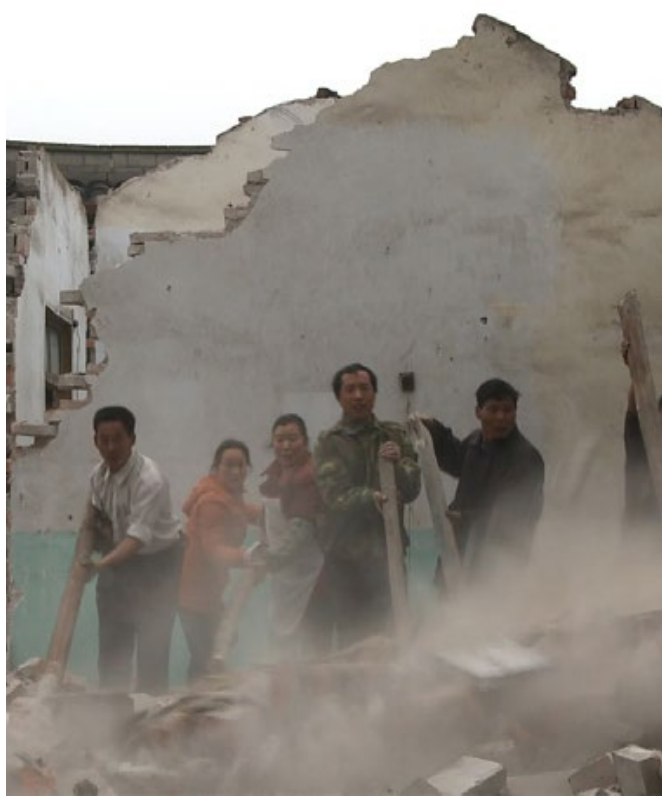

Still from Red White, by Chen Zhong.

\section{Documenting the Earthquake}

\section{Marina SVENSSON}

Unlike previous disasters in China, the Sichuan earthquake was extensively documented in images and film, leaving behind an archive of national trauma unparalleled in Chinese contemporary history. This essay examines 16 documentary films produced by filmmakers in the wake of the disaster. These visual testimonies help preserve individual memories of a traumatic event that to a large extent is unaccounted for in the official media and cultural productions.

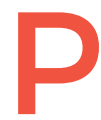

arents and bystanders were among the first to provide footage of the Sichuan earthquake, shakily recorded on their mobile phones and camcorders. In contrast to earlier natural disasters, such as the Tangshan earthquake in 1976, the Sichuan earthquake has been extensively documented in images and on film. To date, at least ten filmmakers have produced 16 independent documentary films on the earthquake and its aftermath. Many filmmakers ended up tracing the ways in which people coped with their experiences during months and even years following the disaster.

\section{Unsilencing Grief}

In late May 2008, directives were issued to domestic media that prevented them from reporting on poor school construction and protesting parents seeking justice for the untimely deaths of their children. The images of desperate families with photos of their dead children kneeling in front of officials, marching to local government buildings, or trying to protect and secure child graves, were only seen in foreign media and, later, in many of the independent documentary films. The lack of transparency and accountability for the deaths, and the silenced voices of the mourning parents, triggered a number of individualsincluding activists such as Tan Zuoren and prominent artist Ai Weiwei-to travel to the disaster zone to gather information. Several independent filmmakers, who felt a strong sense of obligation to record the national trauma, also arrived early to the scene in order to document voices and stories that had been erased in the official media.

Many parents, activists, filmmakers, and concerned citizens thus came to challenge the official narrative of national unity, responsible leadership, heroism, and gratitude that dominated the official media. The filmmakers helped parents to bear witness to their trauma and fight for justice, and in some cases also became engaged in the 
investigations themselves (particularly evident in the case of Ai Xiaoming and Ai Weiwei). Many filmmakers continued to follow events and individuals' stories over the years that followed, documenting not only the official reconstruction effort, but also the struggles of the affected families to overcome their losses, to heal, and rebuild their lives.

\section{Documenting Disaster}

The ten filmmakers discussed in this essay have diverse backgrounds, motivations, and approaches to documentary film (see Box 1 for the list of films and directors). Some of them have a background in film studies or had made several films before they turned their lenses on post-quake Sichuan-examples include Du Haibin, Chen Zhong, Zhao Qi, Fan Jian, and $\mathrm{Mu}$ Zijian. At least three filmmakers come from Sichuan, i.e. Chen Zhong, Ma Zhandong, $\mathrm{Mu}$ Zijian, and thus had knowledge of local dialects and customs, which also show in the deeper engagement their films have with the communities depicted.

Those who arrived early on the scene started filming without having secured any fundingfor instance, Du Haibin had to borrow a camera as he rushed to the area without preparation. A few of them later managed to get funding from international funding organisations and broadcasters. For example, Fan Jian's film The Next Life (2011) was a coproduction with the Japanese TV station NHK, whereas Zhao Qi's film Fallen City (2014) received funding from a range of institutions, including the IDFA Bertha Fund, Sundance Fund, NHK, ITVS, Knowledge Network, YLE, NRK, and premiered on PBS. Unsurprisingly, those films that received support through international financing are of better technical quality in terms of editing, colouring, and sound, and they have also been more widely screened abroad. Du Haibin's film 1428 was one of the first films produced after the quake, with funding from CNEX, and it received the Best Documentary Award at the
2009 Venice International Film Festival. Other films have had more limited exposure abroad and at various unofficial film festivals in China.

Whereas some filmmakers spent a relatively short period of time in the area, many ended up making several visits over the subsequent years (for example Chen Zhong, Ma Zhandong, Fan Jian, and Zhao Qi). Their films are, therefore, able to probe more deeply into the long-term rebuilding process, and the lasting impacts on individuals, families, and communities touched by the tragedy. The films show different styles and aesthetics, ranging from observational, expository, participatory, to performative modes. Many filmmakers adopted an observational style and engaged with individuals and communities over a long period of time (Chen Zhong, Ma Zhandong, Fan Jian, Zhao Qi, and Mu Zijian). Another group of filmmakers approached the topic from a more activist and expository perspective (Ai Xiaoming and Ai Weiwei). One should, however, distinguish between Ai Xiaoming's more participatory mode of filmmaking, making ample use of the footage shot by local citizens themselves, and Ai Weiwei's more performative and confrontational mode.

There are also differences between the first films made in the aftermath of the disaster and those that documented developments over a longer period of time. The initial films often have a very raw, direct, and fragmented character. This is fitting, as it illustrates how people experience and articulate the first shock and the almost unbearable pain after a major traumatic event-examples include Pan Jianlin's Who Killed Our Children and Du Haibin's 1428. Pan's film documents different voices and accounts of the disaster, providing a sense of the grief and struggles of parents to get answers regarding how and why their children had died, and giving a picture of how chaotic the immediate aftermath of the disaster was. Du's 1428 takes its title from the exact time the earthquake occurred on 8 May. The first footage was shot just a few days after the earthquake struck and provides vivid documentation of the massive scope and extent of the destruction. 

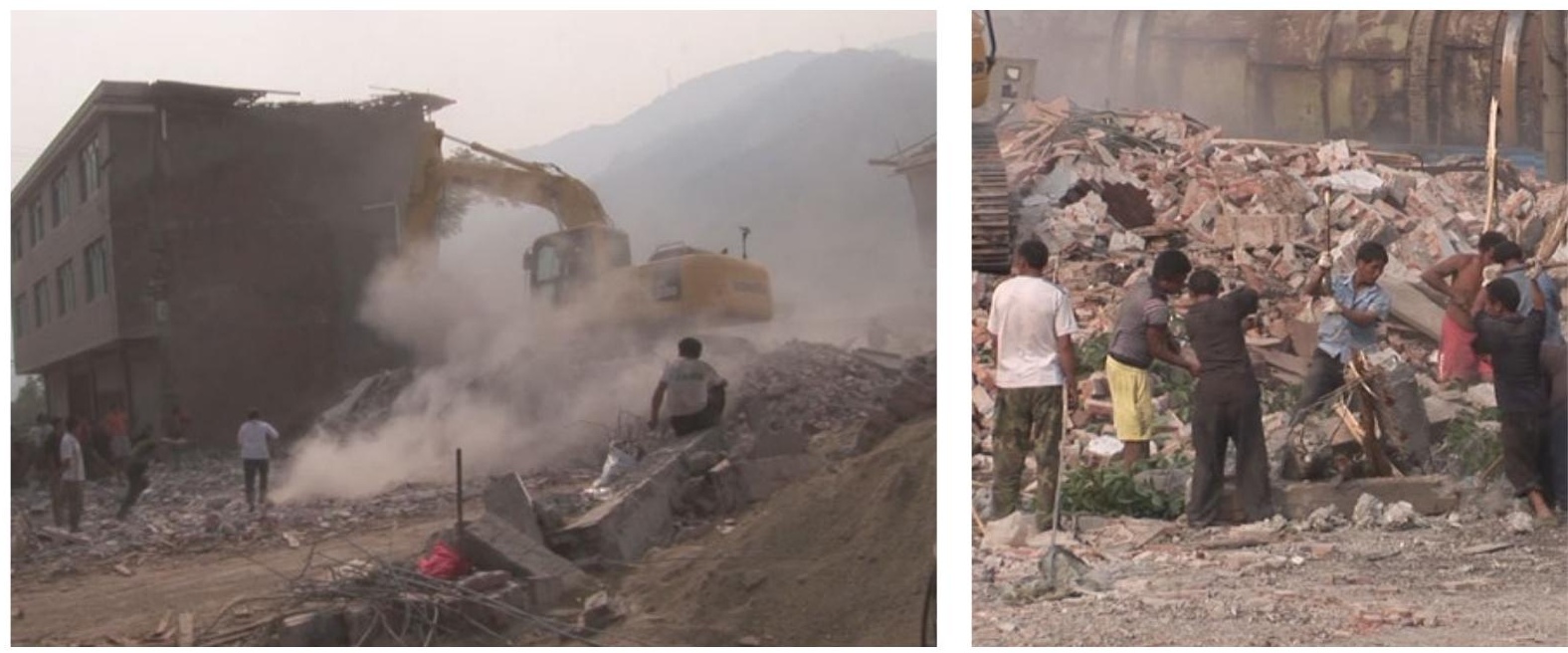

Stills from 7428

documentary by Du

Haibin

The film lacks a main character and storyline, although a father and his son who live in a shack are some of the recurrent figures in the film. The use of powerful imagery of ruins and debris, the lack of voices or an explicit narrative, and the disjointed structure of the film give the viewer a sense of what living in a disaster zone can be like.

Later films, such as those by Chen Zhong, Ma Zhandong, and Fan Jian, among others, focus more on the disaster's impact on individual families and communities. They address their efforts to rebuild their lives, their emotional healing, and their coming to terms with the disaster. A recurrent topic in many of these latter films is the struggle of families to have a second child after the death of their firstborn during the earthquake. In many cases, it was an only child who had died and, while they now were allowed to have a second child, many couples felt emotionally torn over this decision, and in addition had difficulties conceiving. For instance, Fan Jian's film The Next Life depicts the ordeals of a family who lost their eight- year-old daughter and who later, only after several IVF treatments, finally manage to get pregnant again.

The later films also provide fascinating accounts of different customary practices and the role of religion during times of mourning and trauma. For example, in Red, White Chen Zhong focuses on a Daoist temple in Shifang municipality and the role of different ritual and burial practices, which gives his film a strong ethnographic character and shows the important role religion played in the healing process. Some of these later films do not explicitly address the destroyed schools, protests, or calls for justice among parents, but instead show how individuals deal with their loss in more personal and intimate ways. Whereas these movies offer some hope for healing and show human resilience in the face of adversity, the more expository films made by Ai Xiaoming and Ai Weiwei discussed above offer no such comfort. They reveal unhealed (and perhaps unhealable) trauma, lack of redress and official accountability, as well as repression. The argumentative narrative, 

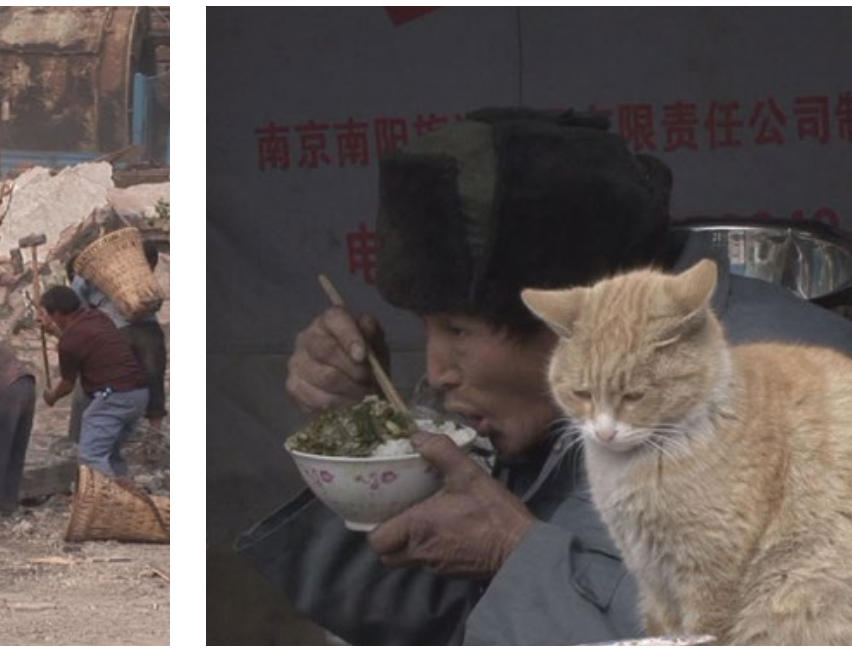

Stills from 7428

documentary by Du

Haibin.

engagement with victims, and confrontation with officials in these films underscores the ways in which filming is a form of civic engagement and social activism for filmmakers such as Ai Xiaoming and Ai Weiwei.

\section{Archiving Trauma}

Although the modes of filming as well as the topics and perspectives are highly variegated, the different films together constitute a valuable repository and archive of national trauma unparalleled in Chinese contemporary history. Whereas documentary films may not help people to get redress, and their circulation in China at the moment is very limited, these visual testimonies help preserve individual memories of a traumatic event that to a large extent is unaccounted for in the official media and cultural productions. They not only provide an important visual repository that will help individual citizens to remember one of China's most devastating

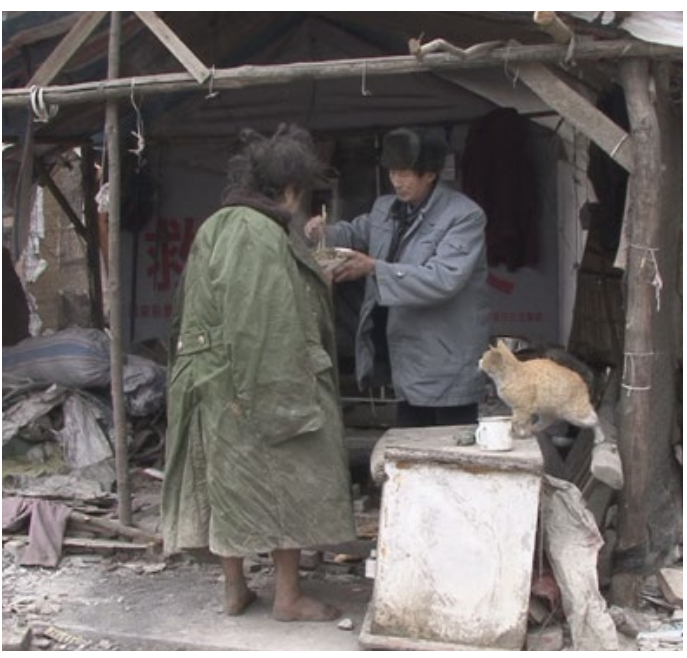

events but also provide important materials for scholars who want to study the sociopolitical context of the earthquake, as well as customs and belief systems in Sichuan.

\section{Documentaries and Filmmakers}

At least ten different filmmakers have together made 16 films documenting the Sichuan earthquake and its aftermath.

Who Killed our Children (Pan Jianlin) Red, White (Chen Zhong)

One Day in May (Ma Zhandong)

Tears in Ashes (Jia Yuchuan)

1428 (Du Haibin)

Our Children; Citizen Investigation; Why are the Flowers so Red; River of Oblivion; Enemy of the State (Ai Xiaoming)

Little Red Cheeks; 4857; Disturbing the Peace (Ai Weiwei)

The Next Life (Fan Jian)

Fallen City (Zhao Qi)

One Child (Mu Zijian) 
This text is taken from Dog Days: A Year of Chinese Labour, Civil Society, and Rights, Made in China Yearbook 2018, edited by Ivan Franceschini and Nicholas Loubere, published 2019 by ANU Press, The Australian National University, Canberra, Australia.

doi.org/10.22459/MIC.04.2019.36 